Pedagogía y Saberes n. ${ }^{\circ} 54$ Universidad Pedagógica Nacional Facultad de Educación. 2021. pp. 155-170

\title{
Género, feminismos y pedagogías de frontera: aportes críticos al espacio educativo*
}

\section{Gender, Feminisms and Border Pedagogies: Critical Contributions to the Educational Space}

Gênero, feminismos e pedagogias de fronteira: contribuições críticas para o espaço educacional

\author{
Juliana Enrico** \\ Alejandra Castro***
}

\section{Para citar este artículo:}

Enrico, J. y Castro, A. (2021). Género, feminismos y pedagogías de frontera: aportes críticos al espacio educativo. Pedagogía y Saberes, (54). https://doi.org/10.17227/pys.num54-10636

* El presente trabajo es producto de una reflexión teórico-metodológica que realizamos como profesoras a cargo del Seminario "El espacio educativo-cultural: territorios, fronteras, imaginarios. Lecturas críticas sobre espacialidad y procesos de subjetivación", de la Licenciatura en Ciencias de la Educación-FFyH UNC; aportando desde nuestras investigaciones respectivas a la construcción de un marco teórico y analítico crítico en torno de acontecimientos y procesos educativo-culturales contemporáneos.

** Doctora en Ciencias de la Educación; investigadora del Consejo Nacional de Investigaciones Científicas y Técnicas (CONICET) del Ministerio de Ciencia, Tecnología e Innovación Productiva de la nación Argentina, con sede en el Centro de Estudios Avanzados (CEA)-FCS UNC; docente de la FFyH UNC.

Correo electrónico: julianaenrico@gmail.com Código Orcid: https://orcid.org/0000-0002-9702-0467

*** Doctora en Ciencias de la Educación; docente e investigadora de la FFyH UNC-CIFFyH UNC.

Correo electrónico:alecastrosanuy@gmail.com ORCID: https://orcid.org/0000-0002-1004-6593 


\title{
Resumen
}

Como lo han conceptualizado desde hace décadas las denominadas pedagogías críticas y de frontera, en diálogo con las prácticas pedagógicas freirianas y con el campo de las alternativas pedagógicas latinoamericanas, el espacio educativo es permeado por una multiplicidad de elementos culturales diversos, transformadores de las lógicas hegemónicas que atraviesan largos procesos históricos. En este marco, los estudios de género y los feminismos junto a las pedagogías críticas y los estudios de subalternidad y traducción, visibilizan una multiplicidad de procesos, sujetos, lenguas, territorios, comunidades, saberes, luchas e identidades (en pugna por no inscribirse dentro de las matrices culturales hegemónicas y de sus principios lingüísticos, pedagógicos, económicos, raciales, culturales, sexuales y genéricos universalizantes). Estos discursos e identidades políticas críticas intervienen en las lógicas epistemológicas y epistémicas del mundo de la vida, atravesando las fronteras de las matrices colonial, capitalista y patriarcal (con incidencia disruptiva en los espacios académicos y sociales, del norte al sur). En el presente trabajo realizaremos una reflexión sobre los aportes de estos espacios al amplio campo transdisciplinario de la educación y a nuestras políticas antagonistas como comunidades democráticas, desde nuestra condición "del sur" del mundo contemporáneo.

\section{Palabras clave}

educación; espacio educativo-cultural; feminismos; género; pedagogías de frontera

\begin{abstract}
As it has been conceptualized for decades by the so-called critical and border pedagogies, and in dialogue with freirean pedagogical practices and with the field of Latin-American pedagogical alternatives, the educational space is permeated by multiple and varied cultural elements that transform the hegemonic logics that pierce through long historical processes. In this context, gender studies and feminisms, together with critical pedagogies, and subaltern and translation studies, make visible a multiplicity of processes, subjects, languages, territories, communities, knowledge, conflicts, and identities (in struggles over recognition from the hegemonic cultural matrixes and their linguistic, pedagogic, economic, racial, cultural, sexual and generic universalizing principles). These critical discourses and political identities intervene in the epistemological and epistemic logics of life, cutting across the borders of patriarchal, capitalist and colonial matrixes (with disruptive incidence in academic and social spaces, from North to South). In this work we will reflect upon the contributions of these spaces and critical theories not only to the large transdisciplinary field of education but also to our antagonist politics as democratic communities in the contemporary world, from our "from the south" condition.
\end{abstract}

\section{Key words}

border pedagogies; education; educational-cultural space; feminisms; gender

\section{Resumo}

Como as chamadas pedagogias críticas e de fronteira tem conceitualizado há décadas, em diálogo com as práticas pedagógicas freirianas e com o campo das alternativas pedagógicas latino-americanas, o espaço educacional é permeado por uma multiplicidade de diversos elementos culturais, transformadores da lógica hegemônica. que passam por longos processos históricos. Nesse contexto, estudos de gênero e feminismos, juntamente com pedagogias críticas e estudos de subalternidade e tradução, tornam visível uma multiplicidade de processos, assuntos, idiomas, territórios, comunidades, conhecimentos, lutas e identidades (na luta para não se registrar nas matrizes culturais hegemônicas e seus princípios linguísticos, pedagógicos, econômicos, raciais, culturais, sexuais e genéricos universalizadores). Esses discursos e identidades políticas críticas intervêm na lógica epistemológica e epistêmica do mundo da vida, atravessando as fronteiras das matrizes colonial, capitalista e patriarcal (com incidência perturbadora nos espaços acadêmicos e sociais, de norte a sul). No presente trabalho, refletiremos sobre as contribuições desses espaços para o amplo campo transdisciplinar da educação e para nossas políticas antagônicas como comunidades democráticas, a partir de nossa condição "no sul” do mundo contemporâneo.

\section{Palavras chave}

educação; espaço educacional-cultural; feminismos; gênero; pedagogias de frontera 


\section{Pedagogías críticas y de frontera}

Con el objetivo de aportar a la construcción de un marco categorial y analítico crítico en torno de acontecimientos y procesos educativo-culturales contemporáneos, retomaremos algunas discusiones que incorporan herramientas conceptuales de diversos campos teóricos, a la luz de las propias transformaciones de los marcos históricos, sociales y culturales que producen nuevas epistemes y epistemologías en el presente.

En su teoría del espacio social, el horizonte transdisciplinario del análisis político del discurso, en cruce con el postestructuralismo y los estudios culturales, nos permite repensar tradiciones, legados y articulaciones centrales en las formaciones históricas y en la configuración de las identidades -en torno de antagonismos irreconciliables e irreductibles-, con eje en la teoría de la hegemonía (Gramsci, 1989; Williams, 1997; Laclau, y Mouffe, 1987).

En clave postmarxista y postfundacional diferentes genealogías y marcos conceptuales son recuperados en esta teorización, que vuelve central la noción de "frontera" como operación discursiva que demarca la identidad. En tal sentido, la noción de antagonismo resulta un significante teórico de gran importancia en los análisis del espacio social, frente a toda mirada universalista ante la que se reinscriben las perspectivas situadas y singulares del conocimiento y del sujeto, en marcos históricos, culturales y geopolíticos específicos y diferenciales (que es necesario situar en nuestros análisis).

El propio objeto "Latinoamérica", desde tal marco, adquiere una especificidad en su propia enunciación discursiva en y desde América Latina, en términos de Puiggrós, demarcándose claramente de los efectos del mundo colonial, capitalista y patriarcal que Sarmiento definiera en el siglo XIX como la imagen de "las auras del Norte", que debían ser reflejadas sobre el sur.

La noción de antagonismo alude a un "exterior constitutivo" (Laclau y Mouffe1987) al que se enfrentan todos los discursos (posibilitando su existencia al demarcar sus límites y establecer sus fronteras identitarias); esta lógica de "no totalidad" o "no sutura" sustenta la elaboración de una teoría de la hegemonía que retoma la senda gramsciana del análisis político en el campo de la filosofía y de la teoría política postmarxistas. En tal sentido, analizamos la noción de diferencia como "origen" de la identidad, para demarcar las operaciones de las alternativas políticas (Aricó, 1985) y de las alternativas pedagógicas (Gramsci, 1998; Puiggrós, 1997; 2015) que definen el horizonte teórico-político crítico de los discursos y experiencias de vida de inscripción latinoamericana, frente al paradigma universalista moderno de la razón occidental.

Revisando los marcos conceptuales sobre la teoría de la dependencia en los países pobres del tercer mundo, al pensar las transformaciones y el crecimiento del mundo global dominado por el capitalismo neoliberal hacia la última década del siglo xx, Adriana Puiggrós resalta las discusiones, en el campo educativo, que se orientaban a deconstruir las nociones marxistas clásicas del campo de las izquierdas políticas, intentando avanzar en interpretaciones discursivas no esencialistas ni universalistas, articulatorias de los procesos educacionales y culturales situados en América Latina.

En tal sentido, Puiggrós menciona que el nuevo imaginario pedagógico que introduce Paulo Freire (quien había sido acusado en los años 60, 70 y 80 de "nomadismo teórico") altera claramente el canon de la pedagogía moderna - atravesando la frontera epistemológica del sur global hacia el norte-, al exponer un tipo de articulación discursiva ininteligible para las lógicas estructurales del poder social y académico (que suponen tanto una inmanencia del poder, como del conocimiento y de los sujetos educadores tradicionales dominantes).

Al respecto Puiggrós afirma que "a diferencia de las pedagogías modernas clásicas, no diseña [Freire] contenidos sino que expone un tipo de relación nueva entre los sujetos, la educación y la política" (1998, p. 132). De allí, sostiene la autora, que ante la crisis de los modelos cerrados y universalistas, la pedagogía de la liberación (en sus diferentes versiones) resulte un encuadre importante en sociedades tan diferentes y distantes como Malasia y Sudáfrica, Filipinas o Bolivia (mencionando especialmente el caso de los indígenas de Chiapas, en México, que han logrado constituirse en un sujeto educador de todo el pueblo mexicano y latinoamericano, interpelando incluso a las máximas autoridades políticas de su país y del mundo).

En este marco es que las luchas de los colectivos sociales - como el del movimiento zapatista, desde su surgimiento en tanto Ejército de Liberación Nacional en 1994 hasta su forma política actual no armada, incluyendo el desplazamiento hacia las formas de gobierno comunitarias organizadas por las mujeres-, adquieren gran relevancia histórica, educativa y cultural en la búsqueda y despliegue de alternativas pedagógicas democráticas radicales.

Las posiciones de los sujetos, devenidas de sus específicas luchas, realidades y situaciones territoriales, se van consolidando o desplazando en función del devenir mismo de las demandas y reivindicaciones 
sociales en contextos dialógicos de enfrentamiento con el modelo de identidad (destructivo) del neoliberalismo; por esto mismo es posible sostener que

[...] ni los sectores sociales privilegiados -clasistas, urbanos, hombres, blancos, parlantes de las lenguas dominantes, adultos - serán siempre y necesariamente los que enseñen, como supone el reproductivismo, ni los sectores desprotegidos - jóvenes, negros, chicanos, indígenas, trabajadores, mujeres, hablantes de lenguas populares tradicionales- continuarán siendo obligatoriamente educandos pasivos del mensaje de los otros. (Puiggrós, 1998, p. 131)

Así como las problemáticas sobre el "tercer mundo" permeaban las discusiones de los años $90 \mathrm{a}$ finales del siglo Xx retomando las tesis de la dependencia, casi treinta años después, en pleno retorno neoliberal en el siglo XXI, las problemáticas sobre el sur global y sobre la realidad de los pueblos y sujetxs oprimidos han impregnado nuestro tiempo. Esta discusión ha sido asumida, entre diversas teorías y espacios de crítica social, por las pedagogías críticas, los estudios culturales y de frontera, los estudios de traducción, los estudios de género y los feminismos contemporáneos. ${ }^{1}$

Por esta vía de argumentación, la propia noción de "tercer mundo" se ha transformado profundamente en el contexto de la caída del bloque socialista, y en torno a las lógicas de mundialización económica y cultural, tal como lo analiza Puiggrós. Peter McLaren sostiene que los procesos de colonización "se han vuelto transnacionales y corporativos", no obstante el capitalismo en sí mismo lleva dentro de sí "las semillas de su vulnerabilidad"; por eso mismo el

$1 \quad$ Al pensar el curriculum como "política cultural", Giroux y McLaren (1998) cuestionan las formas históricas en que la dominación y la subordinación son introducidas en el lenguaje, en los textos y en las prácticas sociales, -que permean la teoría tradicional del curriculum,- mediante "exclusiones" que el espacio educativo debe cuestionar y transformar (desde un horizonte pedagógico democrático y emancipatorio que pueda abordar los "fundamentales antagonismos" que constituyen relaciones sociales de desigualdad y poder, atravesadas por condicionamientos de raza, clase, sexo); donde "la cultura es frecuentemente reducida a un artefacto que da cuerpo a los valores de los grupos dominantes" (Giroux en Giroux y McLaren, 1998, p. 80); y donde la ideología dominante en educación "raramente cuestiona la relación entre conocimiento y poder, o entre cultura y política". En este mismo marco de crítica cultural, la teoría queer (al calor de las intervenciones y movimientos LGTBIQ+) piensa la relación entre lenguaje, poder e identidad desde la crítica cultural y filosófica del sistema sexogenérico heterosexista. Dicha teorización impregna diferentes campos de conocimiento, dando lugar a la intervención feminista transfronteriza cuir "del sur", y a "pedagogías y metodologías queer-cuir", que se inscriben en la tradición interseccional y transgresiva del feminismo negro del tercer mundo, así como en la pedagogía freiriana de la libertad. modo en que McLaren piensa estas nociones pone en crisis sus usos tradicionales (como las epistemologías del sur ponen en crisis hoy la geopolítica territorial del mundo, encontrando sures oprimidos por todas partes, que estallan los límites de las cartografías modernas y las fronteras geopolíticas de los Estados-nación).

En tal sentido nos preguntamos, por ejemplo, si el sur del Río Bravo (como lo analiza Gloria Anzaldúa en Borderlands), ex territorio del norte mexicano, hoy perteneciente al sur norteamericano que se ha apropiado de estas grandes extensiones de tierras desde 1848 (interponiendo en el presente muros mortales en el límite con el México actual), no es tanto un sur norteamericano chicano como un sur en el sentido "de abajo" de las metáforas del México profundo perdido en el tiempo, extirpado de su propio locus de identidad y de su cultura - con sus lenguas, comunidades e historias expropiadas, borradas y eliminadas del mundo de la vida-. ${ }^{2}$

2 Anzaldúa (1999 [1987]) introduce en tal sentido una pedagogía feminista de tipo testimonial (Enrico, 2018b). Desde estas mismas políticas de inclusión lingüística e intercultural que sostiene la autora hacia los años 80 en la academia norteamericana -resaltando las voces consideradas "ilegítimas" o "malhabladas", "mestizas", excluidas del canon letrado moderno (al que le interpone auto-narrativas y contra-narrativas que mezclan el inglés, el español y el náhuatl) —, recomendamos el reciente trabajo Voces de la alterida (Ruiz, et ál, 2017). Este texto expone las voces de estudiantes de pueblos originarios de la Universidad Iberoamericana de México (entre las lenguas de las identidades maya k'iche, ñuu savi, quechua y tsotsil); frente al inglés y el español dominantes en las academias del norte y ante sus implicancias en las culturas, discursos e identidades del norte global. Un importante trabajo que enlaza teoría crítica y pedagogía desde el punto de vista feminista de la autobiografía académica, es el de Marisa Belausteguigoitia (narrativa en la que aparecen como temas centrales las tensiones de "la voz" o "el silencio" en la construcción del sentido, la subjetividad y la experiencia). Belausteguigoitia retoma, situada en la academia norteamericana en clave latinoamericana, desde México, “[...] a aquellos sujetos cuya intención es la sobrevivencia, emergencia y potencia de la voz en escenarios de resistencia intensos como son las minorías en las fronteras de la nación (chicanos, negros, indígenas, mujeres)" (Belausteguigoitia, 2012, p. 482), frente al canon académico de la ciudad letrada occidental. Desde una "pedagogía negativa" que incorpora la teoría crítica, los estudios de género y los estudios culturales, insta a las "interrupciones" de la "pulsión educativa" por el "decir bien", fracturando el "habla educativa" dominante para dar lugar de enunciación a los cruces de lenguas "malhabladas", malditas, del margen, atravesando los límites mismos de las disciplinas y del canon hegemónico eurocéntrico. Entre estos abordajes críticos, recomendamos también la compilación sobre feminismos postcoloniales de Karina Bidaseca y Vanesa Vázquez Laba (2011), quienes dialogan junto con las voces de las mujeres indígenas del sur -en particular, de mapuches del sur de la Argentina-. 
De esta forma, las pedagogías border o de frontera (Puiggrós, 1998; 2013) aparecen intensamente atravesadas por estas condiciones propias de las lógicas imperiales y coloniales de apropiación, migración, mestizaje, hibridación, multiculturalismo, entre lenguas malhabladas y prácticas transfronterizas cada vez más características de las relaciones del mundo global desterritorializado. ${ }^{3}$.

Por ejemplo, refiere Puiggrós en relación al análisis de McLaren, "[...] muchas de las consignas de las feministas norteamericanas pueden ser apropiadas por las mujeres brasileñas en su lucha contra la opresión patriarcal" [tanto como] la cultura chicano/ anglo/americana se extiende al tercer mundo" (Puiggrós, 1998, pp. 151-152), más allá del Río Bravo, del Río Grande o del Paraná. Así, en tal marco se producen los movimientos y las teorías y pedagogías queer y cuir - por fuera y frente a las identidades y espacios culturales metropolitanos centrales, con eje en las alteridades y en las voces oprimidas que denuncian un daño estructural sobre comunidades, pueblos, territorios, sexualidades y experiencias de vida vulneradas y arrasadas-. En tal sentido, Puiggrós destaca la operación crítica de Gloria Anzaldúa como chicana dentro y fuera de Estados Unidos, en sus narrativas y diálogos desde la condición de "tercermundista", mestiza, mujer de color y lesbiana que introduce la práctica y la crítica teórica feminista transfronteriza dentro de la misma academia norteamericana. ${ }^{4}$

En este mismo espacio transfronterizo en clave pedagógica y cultural alternativa o contrahegemónica, Puiggrós afirma

McLaren destaca a Paulo Freire como un referente del tercer mundo que se desborda. Aunque se niega a clasificar al pedagogo brasileño como postestructuralista reconoce la adscripción de muchas de sus ideas a esa corriente, en particular su énfasis en las relaciones entre lenguaje, experiencia, poder e identidad. Afirma que la íntima relación entre poder y lenguaje es generadora de relaciones de poder y también de alternativas. (1998, p. 152) [Énfasis agregado]

3 Tomamos en este texto la noción de "pedagogías críticas y post-críticas" de Tomaz Tadeu Da Silva (1999; 2001), tal como se desarrollará más adelante; y desde esta misma elaboración la noción de "pedagogías de frontera", tal como la han conceptualizado Giroux y McLaren (1998) y Puiggrós (1998; 2013).

4 Un ineludible trabajo de autoras feministas norteamericanas que realizan una revisión en esta misma clave (desde la teoría crítica, la pedagogía freiriana y los estudios de género) abriendo los márgenes de la reflexión educativa en América Latina, es Géneros prófugos. Feminismo y educación, de Marisa Beluasteguigoitia y Araceli Mingo (Comps., 1999). En esta misma compilación, recomendamos el artículo de Henry Giroux "Modernismo, posmodernismo y feminismo. Pensar de nuevo las fronteras del discurso educativo".
Analiza en tal sentido la autora que los procesos de mundialización de los medios de comunicación social rearticulan la sumisión a los intereses financieros internacionales y multinacionales; hoy, en particular, agregaríamos que frente al enorme poder de los multimedios a escala global, la ilimitada profusión de emisiones de mensajes (y su instantáneo y masivo poder de difusión por parte de una diversidad de sujetos políticos y sociales desde las redes, en el marco de la web 2.0 y de los formatos digitales, multimediales y transmedia 3.0) desplaza, transforma, atraviesa y multiplica sin medida y sin límites los ejes de los centros del poder de la información mundial, tanto como sus lenguajes y contenidos. ${ }^{5}$

Por esta vía de argumentación, Puiggrós asegura que

los medios electrónicos han llevado a un plano común lo específico y lo general, hecho que ha producido, al mismo tiempo, la reorganización y liberación de la diferencia. Este proceso contiene posibilidades para la producción de alternativas, pero también peligros. (1998, p. 153)

entre los cuales McLaren menciona entonces "la fragmentación y la disolución de las culturas populares, limitando la convergencia entre la producción intelectual, la formación de una nueva moral económica y la expansión de los nuevos movimientos sociales". Por otra parte, el autor analiza que "la desagregación de las esferas públicas y la masificación de las identidades mestizas vuelve difícil el establecimiento de las solidaridades necesarias para desarrollar lenguajes liberadores que contribuyan a la liberación social” ( McLaren, 1993, p. 9, en Puiggrós, $1998,153){ }^{6}$

5 Incluso, en torno de referentes históricos y sociales "dudosos" y de autorías in-identificables (dado que las redes, la era de la postfotografía y los marcos culturales contemporáneos de postverdad posibilitan la invención y profusión de mensajes irreales o falsos (de tal realismo formal y estético que aparecen como "verdaderos"), instalando tendencias y tópicos que se vuelven masivos a escala global — siendo indistinguible su fuente, origen y procedencia, tal como lo analiza Jameson en su noción de pastiche-. Este tipo de producciones genera fuertes efectos de sentido y "verdad", lo cual se ha comprobado recientemente, por dar un ejemplo resonante, en las campañas electorales de Estados Unidos; por tanto, abre todo un campo de análisis político, cultural y educativo de urgente reflexión.

6 El texto citado por Puiggrós es Freirean Pedagogy and Higer Education. The challenge of Posmodernism and the politics of race. En este mismo marco es necesario mencionar los aportes del espacio de los estudios culturales marxistas (en particular, Williams, Hall, Jameson) en la configuración del área de pedagogía crítica de los estudios culturales norteamericanos (en particular, Giroux, McLaren, Torres). Y es de relevancia que en este horizonte de diálogo teórico y cultural, así como junto a Freire, se inscribe la especificidad situada de las poéticas, narrativas y producciones teóricas de las feministas tercermundistas "de color" (hooks, Anzaldúa, Sandoval, etc.). 
Hoy estas luchas por el sentido chocan fuertemente entre unas y otras formas de poder e identidad. Así, continúa en su análisis de este contexto Puiggrós:

McLaren critica fuertemente a los intelectuales estadounidenses por su incapacidad de articular su producción con la sociedad, y les exige ser conscientes del nuevo colonialismo y la explotación social y transmitir esa conciencia a sus estudiantes [...] advierte que los grandes relatos y las prácticas colonizadoras impiden establecer sistemas de reconocimiento de las múltiples diferencias y representarlas. Con el objetivo de superar ese escollo, propone que los intelectuales críticos construyan un discurso que trascienda las epistemes existentes e interprete las diferentes culturas y lenguajes. El rol de los educadores críticos sería el de traductores que dialogan con los otros, en lugar de intentar representarlos. (Puiggrós, 1998, p. 153)

\section{Tramas emancipatorias entre educación popular y feminismos}

En esta misma línea de análisis de aportes críticos al espacio educativo, si retomamos diversas tensiones y concepciones entre las formas de vida de los pueblos y sociedades, nos parece central destacar la operación que Lugones (2008) denomina la "colonialidad del género". Lugones piensa procesos de larga duración de subalternidad y opresión a la luz de la interseccionalidad de condiciones de raza, género, clase, sexualidad, pero especialmente desde la realidad de las mujeres racializadas "de color" - aquí Brasil constituye un caso especial, remarcado además por la diferencialidad de su lengua "otra" (el portugués) en la América Latina de habla hispana y "tercermundistas" — - víctimas del

7 Textos fundacionales de las feministas "negras" y "de color" ("tercermundistas") son las antologías Esta puente mi espalda y posteriormente Otras inapropiables. Feminismos desde las fronteras. Permeadas por los estudios culturales, la crítica post colonial y la pedagogía del oprimido, dichas intervenciones y discusiones abren una perspectiva analítica desde la crítica feminista a las matrices de identidad coloniales, capitalistas, heterosexistas y patriarcales (e incluso al propio mundo académico predominantemente "masculino" y "blanco"); espacio en el que se articulan los estudios de mujeres, los estudios de frontera y de traducción, los estudios culturales y las áreas de pedagogía crítica. This brigde called my back... [1981], cuya primera traducción al español en 1988 se publica bajo el título Esta puente mi espalda: voces de mujeres tercermundistas en los Estados Unidos, es editado por Cherríe Moraga y Ana Castillo, y contiene textos de Gloria Anzaldúa, bell hooks, Audre Lorde, etc. Esta antología abre con "El poema de la puente" de Kate Rushin —marcando una clara perturbación semántica, gramatical, textual, traductiva一, y reúne ensayos, teoría, narraciones, ilustraciones y poemas escritos por mujeres de ascendencia chicana, latina, indígena, asiática y afro-americana (mujeres "mestizas", "negras", "lesbianas", "tercermundistas") que viven en Norteamérica, bajo el signo de "lo otro" de Occidente (invisibilizadas, oprimidas y subalternizadas por el orden colonial-patriarcal-capitalista global, e incluso por el orden cultural y académico mundo blanco moderno occidental, aún desde dentro del norte global norteamericano. Justamente, desde la vivencia existencial de estos intensos enfrentamientos y tramas es que las feministas postcoloniales y decoloniales buscan visibilizar y deconstruir históricas condiciones de opresión invisibilizadas por las culturas y relatos hegemónicos, profundizando la crítica a la colonialidad del poder-saber-ser teorizada por Quijano (2000).

La interacción cultural de la crítica decolonial y las prácticas feministas populares frente a estas históricas experiencias de opresión, en tanto "coalición orgánica" entre mujeres (negras, indígenas, mestizas, otrxs) resiste la dominación y las opresiones múltiples (coloniales, heteropatriarcales y capitalistas), creando una conciencia crítica y un espacio crítico contra-cultural ${ }^{8}$ - que articula las prácticas académicas, el activismo político y las prácticas artísticas en tanto alteridad epistémica y epistemológica-.

Lugones, en su carácter de filósofa, feminista, activista y educadora popular, remarca justamente desde la noción de interseccionalidad (que retoma de las conceptualizaciones de Spelman, 1988; Brown, 1991; Crenshaw, 1995, en Lugones, 2008, p. 76) la "inseparabilidad" de categorías teóricas que, aún diferenciadas analíticamente, son indivisibles en tanto se

hegemónico que las confina a la diferencia y la desigualdad económica, social y sexual o de género). Este tipo de textos produce una evidente diferenciación lingüística y cultural al situarse en la enunciación del inbetween entre culturas y lenguas, mostrando la experiencia y los saberes "otros" desde un discurso propio de las fronteras que genera una especial operación de enunciación, traducción, mestizaje, hibridación, conocimiento y resignificación cultural con importantes efectos en las matrices de identidad y poder dominantes.

Otras inapropiables. Feminismos desde las fronteras - antología de textos de bell hooks, Avthar Brah, Chela Sandoval, Gloria Anzaldúa, entre otras autoras- también muestra esta operación discursiva transfronteriza que, contra la realidad de una opresión múltiple y sistemática, despliega una "metodología de los oprimidos y de las oprimidas", tal como lo expone Sandoval (2004, p. 81); o una "conciencia mestiza" (Anzaldúa, 1999), que busca concientizar el gesto "diaspórico" y de desplazamiento constante hacia las "formas opositivas o antagónicas de la praxis" (lo cual lleva a la denuncia y transformación de las condiciones históricas de opresión y violencia, y de la exigida "supervivencia" a la dignidad de la vida) (Enrico, 2020).

8 Aludimos a las nociones de contrahegemonía y de contracultura retomando los aportes de Gramsci y de los estudios culturales marxistas (dada su importante influencia interdisciplinaria en el campo de las ciencias sociales y humanas y en las pedagogías críticas, desde los años 60 del siglo xx. En particular, mediante sus elaboraciones del vínculo ideología-poder-cultura-sociedad-lenguaje-identidad; así como de su especial foco en los sujetos "subalternos" para pensar la transformación social "desde abajo" o desde el margen de las formaciones históricas (Gramsci 1989; Williams 1997; Hall 1996; 2010; Jameson 1995). 
traman e intensifican de forma violenta y fatal; por tanto, su ocultamiento revela ejercicios de dominación violentos, y no solo violencias epistemológicas y representacionales en los análisis del mundo.

Así, traición, complicidad, colaboración, silencio entre hombres y mujeres colonizados del mismo modo desde la perspectiva histórica, aunque con muy distintos efectos de acuerdo con sus condiciones de vida singulares-, son parte de mecanismos igualmente opresivos que configuran la complejidad de niveles de los poderes globales y de los actores, instituciones y sujetos que ejercen y detentan diversas violencias sobre grandes poblaciones en todo el mundo.

Así, Lugones considera que "en particular, la teorización de la dominación global continúa llevándose a cabo como si no hiciera falta reconocer y resistir traiciones y colaboraciones de este tipo" (2008, p. 76), que constituyen lo profundo de la imposición del "sistema moderno-colonial de género", tanto "en trazos generales como en su concretitud detallada y vivida". De esta forma, sostiene la autora, en relación con escalas y situaciones micropolíticas:

La educación popular puede ser un método colectivo para explorar críticamente este sistema de género en sus grandes trazos pero, lo que es más importante, también en su detallada concretitud espacio-temporal para así movernos hacia una transformación de las relaciones comunales. (Lugones, 2008, p. 77)

De igual forma, Lugones visibiliza la intersección del género en el análisis del espacio social, por ende, la situación colonial y de clase de las mujeres e identidades de género disidentes y del sur, por ejemplo (en torno de procesos patriarcales y capitalistas euro-norte-centrados bajo los cuales hemos sido y somos educadxs dentro del sistema de hegemonía del capitalismo mundial heteropatriarcal) encuentra en las epistemologías y feminismos del sur ${ }^{9}$ una especial mirada desde y hacia sus propias condiciones de vida situadas y oprimidas, en torno a específicos saberes y prácticas otras, liberadoras del pacto de subalternidad.

Las nociones de "identidades múltiples" (hypenated identities) y "yoes diversificados" (multiple selves) que introduce la autora se relacionan con prácticas y efectos drag, de alternancia y transgresión de género y experimentación multilingüe, contra la opresión de las lógicas de la pureza identitaria; lo cual produce "nue-

9 Tanto Boaventura de Souza Santos como Rita Segato, Alejandra Ciriza y Karina Bidaseca, entre otrxs autorxs, elaboran estas epistemologías situadas, en el marco de una perspectiva postcolonial-decolonial- del-desde el sur (Bidaseca, et ál, 2018). vos mundos" de experiencia (justamente, a través de las narrativas "otras" y desde la conciencia y expresión de sus múltiples intersecciones y aberturas).

Recordemos que en los años 80 del siglo Xx en las academias norteamericanas y canadienses se abría este fuerte proceso de incorporación y traducción interlingüística e intercultural con eje en las narrativas y escrituras de las "mujeres de color" tercermundistas. Dentro de esta genealogía, Lugones se reconoce como "torta" y "mestiza" y retoma de Gloria Anzaldúa la importancia de habitar el borde, pero desde dentro del borde y desde los intersticios en tanto espacios liminales que son enormes (ya que el borde en sí mismo "se nos mete por adentro como espinas de metal, nos divide y nos deshace", Lacombe (2016)). De este modo, pensar y sentir desde la alteridad y desde los espacios comunitarios en plena permeabilidad entre unxs y otrxs, deshace las operaciones hegemónicas de opresión (universalizantes respecto al paradigma de identidad de los poderes centrales), al estallar — tanto como los límites nacionales y culturales- los límites entre los cuerpos, el saber, el ser y el mundo.

En el marco de una perspectiva geográfica, filosófica, política y de género, Doreen Massey introduce desde el contexto británico marxista europeo nociones epistemológicamente muy cercanas en relación con los temas del poder, la espacialidad y los territorios físicos e identitarios (al pensar procesos contemporáneos de migración, diáspora y cruce de fronteras), interrogando sus atravesamientos puntuales tanto en la "especificidad local" como en la "perspectiva internacional", o "desde lo inmenso global hasta lo ínfimo de la intimidad" (Massey, 2005, p. 104).

En tal sentido, piensa la "multiplicidad" y la "pluralidad" como constitutivas de las relaciones de espacialidad, más allá de la simultaneidad temporal de los procesos y acontecimientos en que es necesario visualizar desplazamientos, rupturas y desfasajes en la contemporaneidad (retomando los aportes "antisustancialistas" de los estudios postestructuralistas, postcoloniales, el nomadismo, la teoría queer y la democracia radical, tal como la postulan Laclau y Mouffe, en particular Mouffe). ${ }^{10}$ Dicha operación nos permite el análisis de las diferencias en la territorialidad social y subjetiva, y de la multiplicidad de trayectorias en marcos espaciales e identitarios diversos.

10 Dicho análisis se encuentra en Massey (2005). Recomendamos en particular el texto Mouffe "Feminismo, ciudadanía y política democrática radical" (Mouffe, 1999). El cual fue publicado originalmente en Butler, et ál. (1992). 
Desde esta perspectiva "territorial", entonces, nos interesa pensar tales intervenciones críticas en el contexto de las operaciones "contra-culturales" feministas que conceptualiza en la actualidad Segato frente a las crecientes "pedagogías de la crueldad" $(2010 ; 2016)$ que institucionalizan las violencias de género, machistas, patriarcales, sexuales - hasta volverlas naturales y funcionales a la formación de cuerpos y espíritus dóciles y esclavos, aún en nombre de los poderes de los Estados democráticos. ${ }^{11}$

Tanto Segato $(2010 ; 2016)$ como Ciriza (2017) sostienen las hipótesis no solo del mito fundador universal que da origen a "la mujer", en tanto subalternizada respecto del hombre (por tanto, se debe afirmar culturalmente, en la larga temporalidad histórica y en paralelo con los procesos de discriminación racial, esta "inferioridad" o "debilidad" que no es natural a los linajes humanos); sino también la hipótesis de la continuidad de la colonialidad frente a las posturas historiográficas que afirman el corte del colonialismo en la época de las independencias latinoamericanas, ante el surgimiento de los Estados-nación "libres" y "soberanos".

Nuestras sociedades modernas, afirman, no hicieron sino reproducir sistemáticamente la matriz colonial del poder; no obstante es fundamental intentar analizar que estas matrices de identidad, violentas y opresoras, no ejercieron ni ejercen su poder del mismo modo de acuerdo con las diferenciales condiciones de vida de los sujetos, cuerpos y comunidades (del norte o del sur, de arriba o de abajo, del centro o de la periferia, hombres o mujeres, blancos, negros, pobres, mestizos, diverses, trans, queer, cuir, sudacas, etc.); de

11 En tal sentido, interrogamos el vínculo entre políticas de Estado recientes de la nación Argentina contra las violencias hacia las mujeres e identidades de género diversas y disidentes (en particular, "macropolíticas", nuevas legislaciones y programas educativos nacionales del período kirchnerista, que mencionamos en otros análisis), junto con el dispositivo de visibilización, denuncia y sanción social de casos y experiencias de violencia de género llevado adelante en el país desde la irrupción del colectivo feminista "Ni una menos", que logró emerger e instituirse fuertemente en el espacio público en la última década (y en la Argentina en particular desde 2015, convocando desde las redes sociales a marchas que se volvieron multitudinarias en todo el país), dadas las crecientes estadísticas de feminicidios (instancia extrema de la violencia de género) registradas en nuestro territorio. El movimiento "Ni una menos" ha logrado visibilizar "desde abajo" y desde acciones culturales y pedagógicas "micropolíticas" (que fueron tomando cuerpo y organizándose crecientemente de forma masiva), vivencias particulares y datos no visibles en las estadísticas oficiales, mediante la tematización y condena social de la problemática de las violencias históricas hacia la población femenina o de mujeres y comunidades LGTBIQ+ (afirmando un sentido amplio del cuerpo-identidad-mujer, como significante político, y de toda diversidad e identidad de género subalternizada, abyecta u oprimida). igual forma, dependen de la autonomía de los pueblos y sociedades que tienen el poder de ruptura y transformación de la opresión, mediante la elaboración y transmisión de prácticas políticas contra-culturales liberadoras, educativas, ecológicas, económicas, sociales, sexuales, subjetivas (Enrico, 2018a; 2018b).

Sobre estos mismos ejes las pedagogías críticas, ${ }^{12}$ en tanto "prácticas contrahegemónicas" que conciben al campo cultural como "arena de lucha y resistencia" (McLaren, 1988; Giroux, 1998) vienen haciendo un trabajo desde los territorios, abriendo todo un espectro de alternativas epistemológicas, epistémicas y pedagógicas (de los oprimidos, de frontera, del margen, disidentes, populares, socialistas, feministas, transgresoras, de la diferencia, queer, cuir) que se han ido diseminando y tematizando con mayor especificidad a lo largo de Latinoamérica (y del sur global) en las últimas décadas (biografiando y des-biografiando las historias y experiencias de comunidades, pueblos y sujetxs), no solo al estudiar e indagar sus narrativas sino abriendo el espacio discursivo-social a la enunciación de diversas "auto-narrativas" (Anzaldúa, 1999) y "saberes otros" por parte de los propios actores sociales desde sus locus subjetivos. Esta escena introdujo un campo de nuevas subjetividades y sujetxs nombrándose a sí mismos, o intentando enunciar su cambiante "mismidad" y su diferencia con voz propia, intercambiando sus saberes y experiencias en condiciones de igualdad epistémica y política, sin responder necesariamente a ninguna herencia absoluta y asumiendo el lugar de sujetos de enunciación más que de objetos de estudio del campo de las ciencias sociales y humanas.

Desde tal marco, los feminismos del sur y decoloniales comprenden una multiplicidad de discursos que visibilizan y nombran las ancestrales e históricas opresiones hacia las mujeres (y sujetxs LGTBIQ+) a lo largo de la porción continental del sur global, frente a la matriz cultural que Mignolo (2003) conceptualiza como la colonialidad del poder ${ }^{13}$ (que define un

12 En particular, el área de pedagogía crítica de los estudios culturales anglosajones y su gran influencia en América Latina, tanto como la de Freire: McLaren, Giroux, Carlos Torres; Puiggrós y el marco de APPeAL, etc. En relación con la obra de Freire y con su noción de educación popular, seguimos en particular los estudios de Rosa María Torres, Adriana Puiggrós y Lidia Rodríguez (Enrico, 2020).

13 En tal sentido, Mignolo retoma la noción de Quijano y, dentro de los procesos históricos de la colonialidad del poder, define las geopolíticas de conocimiento de la modernidad (ante las cuales resalta la operación crítica decolonial del pensamiento de frontera, los conocimientos subalternos y la desobediencia epistémica frente a la matriz cultural del sistema moderno-colonial). En este marco epistémico hacia el margen, el pensamiento fronterizo implicaría procesos de liberación subjetiva 
"poder de enunciación" de ciertos grupos humanos dominantes). Por esta vía, la crítica teórica feminista Gayatri Chakravorty Spivak (1998) enuncia, desde una perspectiva post-colonial, cómo la matriz subjetiva-colonial-moderna doblemente subalterna de las mujeres de sociedades que vivieron (y sufrieron) la conquista y el colonialismo.

\section{Las teorías post-críticas y el insight del afuera en el espacio educativo: crítica de la desigualdad y afirmación de las diferencias}

Justamente, cuando desde las teorías y pedagogías post-críticas de la educación y del curriculum Tadeu da Silva $(1999 ; 2001)$ interroga la compleja institución de "espacios de identidad", al cuestionar los criterios de poder presentes y latentes en la incorporación de ciertos contenidos al curriculum -y en la no incorporación de otros saberes y conocimientos-, toca a su vez el nudo de la relación entre poder y conocimiento, y entre poder, saber e identidad en la configuración de sistemas de sentido y de vida. Por eso recupera la articulación de los aportes de los feminismos, de la teoría crítica, del posestructuralismo, los estudios postcoloniales y los estudios culturales para el abordaje complejo de la teoría social y del espacio educativo, en contextos de deriva de los pueblos y de los sujetos. Analizando estos aportes críticos, afirma:

La perspectiva feminista implica [...] una verdadera transformación epistemológica. Amplía el insight, desarrollado en ciertas vertientes del marxismo y en la sociología del conocimiento, de que la epistemología es siempre una cuestión de posición. Dependiendo de dónde estoy situado, conozco ciertas cosas y no otras. No se trata solamente de una cuestión de acceso, sino de perspectiva. (Tadeu da Silva, 1999, p. 48)

y social. Del mismo modo, Mignolo (2003) retoma la distinción entre explotación-dominación, tal como la reelabora Dussel en torno de la noción de "dependencia" al releer a Marx (lo cual define las específicas operaciones de opresión del capitalismo central metropolitano hacia el "Tercer mundo", y hace necesario diferenciar la especificidad de la teoría de la dependencia que surge hacia los años 60 del siglo xx en Latinoamérica, a partir de sus históricas condiciones de dominación, tanto económicas como culturales). En este contexto Dussel se perfila como uno de los principales autores y referentes de la teología de la liberación y de la filosofía de la liberación latinoamericanas (junto con Kusch, Roig, Zea, Cullen) desde su surgimiento en los años 70. Dicha perspectiva da origen a una específica corriente de pensamiento filosófico latinoamericano.
Del mismo modo, Tadeu da Silva plantea que el "sesgo representacional" que vuelve problemático el concepto mismo de teoría introduce la necesidad de interrogar toda otra escena que no puede reducirse al simbolismo lingüístico, ni al orden conceptual desde la perspectiva del conocimiento (siendo que la propia operación de la teoría es la performatividad de la realidad, en tanto efecto de mirada, de visión, de categorización, y por ende de significación sobre el mundo). "De acuerdo con esa visión, es imposible separar la descripción simbólica, lingüística, de la realidad —esto es, la teoría- de sus efectos de realidad" (Tadeu da Silva, 1999, p. 3).

En tal sentido Tadeu da Silva resalta la conceptualización de Giroux del curriculum como "política cultural", bajo el fuerte influjo de la teoría crítica frankfurtiana que permea los estudios culturales ingleses y norteamericanos. Desde este marco teórico crítico, Giroux liga profundamente al campo pedagógico las complejas tramas sociales y culturales más amplias del poder y la desigualdad que atraviesan la complejidad del campo cultural y sus condicionamientos ideológicos, políticos e históricos.

Ahora bien, situado en el contexto de surgimiento de las teorías post-críticas en torno a la tensión entre diferencia e igualdad cultural, Tadeu da Silva analiza que "la creciente visibilidad del movimiento y la teoría feminista, forzó a las perspectivas críticas en educación a concederle creciente importancia al papel del género en la producción de desigualdad" (Tadeu da Silva, 1999, p. 47) asociado tanto al patriarcado como al capitalismo, es decir, tanto a las determinaciones de sexo-género como a los condicionamientos de la división de clases en tanto operaciones fuertes de dominación social, cultural y económica; lo anterior frente a la predominancia de los análisis de las determinaciones de clase en los análisis marxistas clásicos, que habían obturado la lectura transversal de las profundas operaciones e intersecciones de la división de género en tanto matriz cultural histórica -entre las matrices de opresión no presentes ni visibles en el análisis social; a la que se intersecan fuertemente la condición racial en el contexto de procesos de "racialización" y discriminación.

A partir de lo anterior Tadeu da Silva expone:

Al mismo tiempo en que la teoría educacional y curricular reconocía, de forma creciente, la importancia de las cuestiones de género se desarrollaba, en el área originalmente conocida como "Estudios de la Mujer" (Women's Studies), sobre todo en los Estados Unidos, una preocupación por una "pedagogía feminista". (1999, p. 49) 
Este espacio surgido en las academias norteamericanas (tanto en Estados Unidos como en Canadá) fue produciendo un "contrapunto" respecto a las prácticas pedagógicas tradicionales "que eran consideradas como expresión de valores masculinos y patriarcales", elaborando desde el abordaje de múltiples diferencias una multiplicidad de vínculos pedagógicos diversos o antagónicos a las formas tradicionales de establecimiento del poder (y, por tanto, de la identidad).

Sobre el horizonte crítico de la "pedagogía feminista", Tadeu da Silva sostiene que "aún al no estar centrada específicamente en cuestiones curriculares, la pedagogía feminista puede servir de inspiración para una perspectiva curricular preocupada con cuestiones de género, en la medida en que el currículo no puede ser separado de la pedagogía" (p. 50), y por eso es central pensar su función epistemológica y social dentro y fuera de los espacios pedagógicos tradicionales, resaltando su importante y amplio valor educativo-cultural en torno de sus fines democratizantes y emancipatorios.

\section{El giro teórico de los lenguajes feministas}

Al asumir el valor central de los lenguajes en la constitución de los saberes contemporáneos, Boria (2016) plantea la importancia de las teorías feministas en tanto "giro teórico" (Enrico, 2019). Infrecuentemente reconocido como tal en el campo de las ciencias sociales y humanas, no obstante configura un importante aporte a la teoría y el análisis social (Boria, 2016, p. 23); sobre todo a partir de introducir la operación de traducción interlingüística y cultural, como rasgo epistemológico crítico situado que sortea el obstáculo universalista en el acceso al conocimiento y vivencia del mundo. ${ }^{14}$

Por su parte, Nelly Richard destaca la importancia del punto de vista feminista en la teorización de la división de género (en tanto marcación de la diferencia sexual en términos de poder y subordinación) en el contexto de crítica a las epistemologías de las ciencias sociales y humanas. En tal sentido, remarca 1) el cuestionamiento de la teoría feminista al "sistema de institucionalización académica que canonizan las disciplinas" (postulando una mirada transdisciplinaria y transfronteriza frente a escenarios diversos); 2) la

14 En tal sentido, Boria expresa que "[...] en este siglo XxI encontramos 'giros' que se adjudican al cuerpo ('giro corporal'), a los afectos ('giro afectivo'), a los discursos ('giro semiótico'), y hace poco tiempo se habla de 'giro decolonial', cuando en realidad gran parte de esas temáticas ya habían sido propuestas y debatidas por la(s) teoría(s) feminista(s). En todo caso, si aceptamos que los desplazamientos anteriores tratan problemáticas nuevas y originales, al menos deberíamos acordar que el-los feminismo-s producen transformaciones en el modo de ver el mundo y con ello deberían situarse en ese escenario móvil junto con otras teorías del siglo" (Boria, 2016, pp. 23-24; Enrico, 2018a, 2019). importancia de su situacionismo en la elaboración de un conocimiento discursivamente historizado y "corporizado", frente a la pretensión científica universalista del sistema de saber-poder de las hegemonías culturales; y 3) su crítica a la "simbólica del pensamiento" ( Richard, 2012, pp. 34-35) que organiza las representaciones culturales e identitarias, dividiendo jerárquica y reductivamente el espacio social al normar las relaciones entre lo igual y lo diferente (con poder de ruptura en el entramado de las formaciones sociales sedimentadas).

En este marco, la teorización y la operación queer / cuir (Valencia, 2014; Flores, 2017) abre tajos en el pensamiento euro-norte-centrado y falogocéntrico, asumiendo las derivas de comunidades y subjetividades descentradas, distópicas, disidentes y perturbadoras del canon cultural de la matriz colonial, heteropatriarcal, capitalista y racista.

Sayak Valencia sostiene que si lo queer no es una identidad - retomando la noción de Parole de queer, tal como fue pensada y enunciada por Paul Preciado en el contexto de la teorización sobre el movimiento y las multitudes queer por parte de referentes claves como Judith Butler, Teresa de Lauretis y Eve Sedgwick- ${ }^{15}$ en todo caso puede definirse como "un proceso de autocrítica radical y de crítica a la sociedad y a sus categorías absolutas, como lo masculino y lo femenino" (Valencia, 2018, p. 6; Enrico, 2019).

Revisando la etimología de la noción que puede rastrearse hasta el siglo XVI (siendo de probable raíz germánica), queer ha sedimentado históricamente significaciones semejantes dentro del universo semántico de lo "raro", "descentrado" e incluso "perverso". Valencia aporta que, aunque se considera un término exclusivamente anglófono, tiene origen indo-europeo; recién en el siglo xx se incorpora esta noción en forma despectiva para enunciar la homosexualidad masculina, extendiéndose luego a las sexualidades y géneros disidentes, a través de "diversas dimensiones políticas que articularon al movimiento queer, formado en un principio por los devenires minoritarios del tercer mundo estadounidense" (Valencia, 2018, p. 25).

Y aquí es importante mencionar su agudo análisis respecto a cómo este movimiento logra configurar el marco epistemológico de la teoría queer, aún atra-

15 Cuya eficacia política, dice Preciado, consiste en ser la "reapropiación de una injuria y de un uso frente al lenguaje dominante" que nos ha nombrado y constituido como sujetos abyectos y cuyo desplazamiento no opera del mismo modo al estar la palabra queer, en el español, por ejemplo, "desprovista de memoria histórica" (permaneciendo un uso "anglo" en nuestra lengua). Por ende, es fundamental repensar los contextos lingüísticos y las operaciones de traducción al introducirse este significante en otras lenguas y culturas (Preciado, 2018 , p. 17). De aquí el despliegue posterior de lo cuir en su apropiación "desde el sur" o en clave lexical "sudaca". 
vesado de desplazamientos respecto de las escenas centrales que sesgan los sentidos dominantes del mundo anglosajón. Al respecto, Valencia controvierte el uso del término en contextos académicos:

La versión oficial sitúa su uso teórico en 1991 cuando Teresa de Lauretis publica su emblemático artículo "Queer Theory. Lesbian and gay sexualities" en la Revista Differences.

Sin embargo, quizás en la misma lógica del capitalismo académico, que invisibiliza lo minoritario, no se considera como uso "teórico" el que le da Gloria Anzaldúa en su libro La Frontera publicado en 1987. (Valencia, 2018, p. 31)

En este contexto, Valencia sitúa el despliegue y desplazamiento del queer al cuir, mediante el cruce de las fronteras norte-sur que desarma y deslocaliza los territorios e identidades centrales a través del tráfico y el tránsito entre lo global y lo local, en medio de migraciones, diásporas y violencias culturales, económicas, epistémicas, ecológicas, genéricas y sexuales que despedazan todos los mapas, lenguas, comunidades, cuerpos y memorias.

Las lógicas necropolíticas del capitalismo gore (Valencia, 2014) nos exigen repensar siglos de dominación, colonialidad y violencia, presentes en las intermitencias cotidianas y persistentes de las tramas de apropiación sistemática de la-vida-la-muerte (Derrida, 2010) - es decir, de nuestra sobrevivencia como condición permanente de vida limitada por la crueldad de los poderes económicos y políticos que mueven el mundo-, al deslocalizar y dispersar de forma transfronteriza y transnacional sus efectos fáusticos y depredadores.

En tal sentido, Valencia nos llama a enfatizar cómo puede operar en sentido inverso y decolonial la operación cuir:

Las multitudes queer y sus acciones directas e incluso teóricas trascienden la geopolítica del norte en la que se inscriben y activan de manera colectiva la desobediencia crítica del tercer mundo estadounidense frente a las formas subalternizantes del poder hegemónico; creando una coyuntura del desplazamiento geopolítico y epistémico de lo queer a lo cuir, puesto que la tercermundización, como categoría de enunciación de los procesos de subalternización g-local teje redes de intercambio y diálogo posible con el sur. (Valencia, 2018, pp. 40-41)

Y por eso concibe "este sur", ante las consecuencias deshumanizantes, extractivas y violentas de los marcos de explotación del capitalismo contemporáneo, como "un posicionamiento crítico y no solo como un emplazamiento geopolítico, donde, a causa de las lógicas impositivas del capitalismo voraz, el mundo y sus poblaciones están deviniendo sur de forma cada vez más acelerada" (Valencia, 2018, p. 41). Por ende, acentúa la necesidad de una gran insurrección en este contexto de "vulneración extrema" de nuestras vidas (Enrico, 2019).

Aquí también aparece la operación de "cuirización del saber" que propone val flores (2018) - el uso de las minúsculas en el nombre propio, alterando además las mayúsculas que en general enmarcan y resaltan la función autoral, constituye este tipo de intervención y de práctica de frontera (o marginal) respecto del canon académico y literario-. En tal línea, flores plantea la importancia de pensar no tanto "qué es" lo queer o lo cuir, sino "cómo opera" en términos de una crítica y una política cultural radicales, surgidas desde los territorios del sur ocupados, violentados y asediados históricamente. Piensa por tanto "el sur" y "lo cuir" ("sudaca" y precario) como "pliegue táctico", retomando esta noción de Nelly Richard.

\section{Atravesamientos entre pedagogías queer y cuir}

Dentro de las llamadas pedagogías transgresoras (Britzman, et ál., 2018a) y transgresoras cuir (Britzman, et ál., 2018b) la operación crítica intenta cuirizar las prácticas educativas relacionados espacios y situaciones liminales, por lo cual nos interesa interrogar esta intervención política a la luz de un camino pleno de historias de violencias y de claroscuros. Entre estas compilaciones encontramos "la enseñanza de la transgresión" en el marco de la "educación como práctica de la libertad", donde hooks retoma la senda freiriana, ${ }^{16}$ tanto como la tradición del feminismo negro y la clave sexual como un gran campo de la disputa política por la transformación social.

Situadxs en medio mismo de los "intersticios de múltiples mundos y disciplinas" (flores, 2018), la idea es atravesar un espacio transfronterizo "donde se cruzan la vida y la educación, la condición ética y la creación estética, y se entremezclan tradiciones pedagógicas, intensidades subjetivas" (flores, 2018, pp. 144-145) y determinaciones históricas en torno

16 Con traducción de Gabi Herczeg, los dos tomos de Pedagogías transgresoras publicados por Bocavulvaria en 2018, reúnen textos tales como "Eros, erotismo y proceso pedagógico", de bell hooks (publicado originalmente como Teaching to transgress. Education as the practice of freedom (Enseñando a transgredir: la educación como práctica de la libertad [1994]); y "Curiosidad, sexualidad y curriculum", de Deborah Britzman (traducido del inglés al portugués por Tomaz Tadeu da Silva; publicado originalmente como "O corpo educado. Pedagogias da sexualidade” en Lopes Louro, G. (Comp.), 2001. 
de los procesos de formulación de las identidades comunes; allí donde justamente es necesario pensar "qué operaciones epistemológicas, políticas y estéticas" se ponen en funcionamiento en las instituciones para "regular la generización del conocimiento y de los cuerpos" (flores, 2018, p. 87).

Y esta pregunta devenida de una experiencia cuir que busca desbiografiar el rigor de las gramáticas coloniales, justamente abre en el espacio educativo y social una clave de libertad y desujeción respecto de los órdenes dominantes que cristalizan, confinan y opacan nuestros vínculos, nuestros afectos y nuestra felicidad (más allá de nuestra necesaria inscripción en una comunidad).

Cuando ya hacia 1995 Deborah Britzman cuestiona, desde la academia canadiense, los fundamentos mismos del pensamiento educativo en torno de las tensiones y aportes de la teoría queer, intentando interrogar lo radicalmente impensable como dinámica a la que se enfrenta el pensamiento; en este marco de profundización de las lógicas neoliberales a escala global ${ }^{17} \mathrm{y}$ ante la llamada "problemática del

17 En el contexto histórico de surgimiento del movimiento por los derechos civiles en Estados Unidos hacia los años $60 \mathrm{del}$ siglo XX, crecen las luchas por la liberación civil y sexual del movimiento feminista Women Liberation y de gays y lesbianas, sumadas al anti-racismo y a las acciones de paz por la no violencia, lo cual fue produciendo el incremento de derechos civiles y una mayor inclusión social junto a los movimientos de masas, lográndose la no segregación negra — sobre todo en los estados sureños, luego de sangrientas luchas-y el crecimiento de las "multitudes queer". En este marco se produce el avance de la globalización capitalista y de la epidemia por HIV - SIDA en los años 80 (al tiempo en que se desarrollaba la teorización queer en las academias norteamericanas, en el contexto de los activismos políticos, culturales, sexuales y artísticos del momento). Ante el escenario de diferenciación entre el Primer Mundo del norte global y la tercermundización de las poblaciones oprimidas dentro de los grandes centros de poder, y hacia las periferias globales, el mundo enfrenta fuertes conmociones culturales y sociales que atraviesan y estallan las fronteras norte-sur.

Sobre este escenario que tiene origen en los revolucionarios 60, Tadeu da Silva asegura que "como sabemos, la década de los 60 fue una década de grandes agitaciones y transformaciones. Los movimientos de independencia de las antiguas colonias europeas; las protestas estudiantiles en Francia y en otros países; la continuación del movimiento por los derechos civiles en los Estados Unidos; las protestas contra la guerra de Vietnam; los movimientos de contracultura; el movimiento feminista; la liberación sexual; las luchas contra la dictadura militar en Brasil: son algunos de los importantes movimientos sociales y culturales que caracterizaron los años 60 . No por coincidencia fue también en esa década que surgieron libros, ensayos, teorizaciones que pusieron en jaque el pensamiento y la estructura educativa tradicional" (Tadeu da Silva, 1999, p. 13). En nuestro caso es central destacar que, en tal contexto histórico, el pensamiento y la pedagogía de Paulo Freire perforaron la frontera sur-norte ("desde abajo"), contrariamente al tráfico tradicional y hegemónico norte-sur. tercer mundo" (subalternidad, opresión, discriminación racial, de clase y de género) es que aparecen estas subversiones epistemológicas que tienen como insistencia metodológica central el estudio de los límites, las fronteras y la traducción cultural.

En este mismo contexto de configuración de los procesos geopolíticos históricos que atraviesan los escenarios culturales locales y las experiencias situadas de las "arquitecturas de la normalización", también Luhmann interroga las "diluciones de lo extraño", provocadas por procesos de identidad y subjetivación frente a los que piensa la "subversidad" de lo anormal, que no encuentra lugar entre las prácticas de asignación de "posiciones de sujeto" ${ }^{18}$ por parte de los poderes heteronormativos del mundo.

Del mismo modo, Guacira Lopes Louro piensa contemporáneamente desde Brasil, ya atravesando el ocaso del siglo xx y los inicios del siglo XxI, políticas de conocimiento cuir en el cruce entre la teoría feminista y los activismos políticos de los entonces llamados "estudios gays y lésbicos", hoy reconocidos dentro del campo de las disidencias sexo-genéricas.

En esta escena val flores introduce "metodologías queer" entre "esporas de indisciplina" (flores, 2018) que perturban el canon académico y escolar modernos, cuestionando por un lado la heteronorma, y por otro lado la compleja trama de regulaciones y regímenes de disciplinamiento sobre el saber, los cuerpos y los sujetos dentro del campo pedagógico. Ante estas fronteras propone la práctica desgarrada de des-biografiar las experiencias al sacudir de nuestros cuerpos y memorias las gramáticas coloniales, situando tanto las experiencias del daño como las del placer en nuestras vivencias de un mundo compartido (pero siempre impropio e inapropiable), en plena fragilidad del saber y del ser.

En su ars-disidentis, ${ }^{19}$ des-biografiando las tramas de su vida, val flores expresa que, siendo una "post-fugitiva del desierto" (grupo artístico-político de lesbianas feministas de Neuquén, Argentina) y maestra prófuga, heterodoxa, lesbiana masculina, queer, cuir, sudaca, activista de la disidencia sexual, prosexo, practicante de escrituras, ${ }^{20}$ luego de haber

18 Seguimos aquí el análisis de Gabi Herczeg en el prólogo al segundo volumen de Pedagogías Transgresoras (Britzman, 2018b).

19 En diálogo con el planteo de Monique Wittig (quien, en la línea del materialismo francés, mediante su ars erótica sexualis lesbofeminista, "no-mujer", cuestiona lo que denomina "el pensamiento heterosexual", dando forma a la crítica teórica que inaugura el marco queer).

20 Se sugiere su blog "Escritos heréticos": http://escritoshereticos.blogspot.com/ y el análisis en Enrico (2017). 
renunciado a su cargo como maestra titular de escuelas de nivel primario de la provincia de Neuquén, del sur de Argentina (espacio que la privaba de la imaginación, por lo cual decidió "desertar de una sociabilidad mortífera heteronormativa"), inició una camino de destierro y de invención de "talleres sobre feminismos queer, escritura, disidencia sexual, sexualidades y géneros en educación" (flores, 2018, p. 141; Enrico, 2018a; 2018b; 2019). Sobre este espacio flores expresa:

[...] me arrojé de manera rudimentaria al diseño de estos talleres que se fueron armando, precaria e intuitivamente, como dispositivos de autoalteración de la vida, ejercicios de creación colectiva destinados a activar extrañas experiencias de construcción de conocimientos y formas de relación. (2018, p. 142)

Este léxico y esta práctica, claro está, alteran y perturban el canon pedagógico, el poder de las disciplinas y la legibilidad y comunicabilidad de formas de conocimiento y contenidos institucionalizados, curricularizados y ordenados en base a complejidades y jerarquías que tienden a poder ser categorizados, conceptualizados y dilucidados en tanto accesibles, cognoscibles, transmisibles y didactizables; es decir, traducidos de los léxicos científicos de diferentes campos de conocimiento, a las didácticas generales y específicas que hacen posible su enseñanza y transmisión (sobre la base de los procesos de curricularización y transposición didáctica que expone Chevallard). Por ello el antagonismo que implica este "lenguaje" disidente es objetado, cuestionado, impugnado y finalmente abyectado por los discursos de la norma académica y escolar hegemónica (que impugna tanto las formas, imágenes y contenidos "extraños" e "ilegibles", como a lxs sujetxs que portan tal enunciación o desviación de la norma). Es decir que su "diferencialidad" es valorada como inadecuada e impertinente, por "asistemática", "poco seria" e infinidad de argumentos poco serios, dado que los espacios cristalizados de poder - y sus "representantes" - no han indagado el potencial de este tipo de textos, teorizaciones, retóricas, poéticas, experiencias y espacialidades críticas radicales que ponen en escena los efectos de una herida colonial y patriarcal, nunca total pero sí inerradicable (en medio de la búsqueda de una reelaboración colectiva menos hostil a la tematización de las diferencias culturales y subjetivas que en efecto existen y conviven en todo espacio social) Con lo cual las perspectivas duras no pueden dialogar, porque poseen y ostentan fálicamente todo el saber-poder y la verdad (en la forma de un poder "suntuario"); así, conocemos muy bien la literalidad con la que opera la metáfora del falo en los espacios patriarcales de poder (y no hace falta explicarla porque su gesto tiene efectos inmediatos sobre nuestros cuerpos).

Continúa flores mencionando que este tipo de experiencia de los talleres, a partir de la condición de precariedad y vulnerabilidad compartidas, constituye

un ensayo a tientas de procesos creativos para explorar las contingencias de nuestras existencias y afectividades [donde lo colectivo opera] para proyectar ideas, el cuerpo como método de trabajo, la palabra como material plástico y político, y el pensamiento como estética. (Flores, 2018, p. 142)

Al tiempo que cuestiona las matrices históricas de feminización de la docencia y de masculinización de la producción del conocimiento (en medio del "pacto patriarcal" que conceptualiza Segato, con fuertes efectos también en el campo epistemológico y académico), flores cuestiona los marcos de disputas sociales que producen performativamente estas posiciones y estratos, reproduciendo históricas formas de opresión y de control (genérico, social, sexual). Así es que piensa la noción de "esporas de indisciplina" que aparece como gesto de transformación en los talleres, en el contexto de diversas condiciones de posibilidad y de acción, tomando potencia, forma y visibilidad en muy diversos espacios educativos y sociales críticos.

Desde tales intervenciones flores piensa como desleal incluso su propia adscripción a la teoría queer (desde la situación geopolítica cuir, no metropolitana, de los países del sur y del entonces llamado "tercer mundo"); y en tal sentido especifica su traición-traducción-apropiación del universo teórico-político queer "[...] para mis prácticas y políticas desinstitucionalizadas del saber en un contexto sudaca, queer refiere a un modo de (des) hacer, a una práctica de conocimiento, cuerpo y afecto, más que a un sujeto en particular" (Flores, 2018, p. 152).

De este modo, interroga qué hace posible la "operación" queer, cómo funciona, cómo punza la verdad histórica, qué efectos y temblores produce en las narrativas que nos metieron en la cabeza; y propone entonces "cuirizar el saber" desde los territorios del sur del mundo (que hemos sufrido la conquista, los procesos de colonialidad, la imposición de la lengua del imperio y el borramiento atroz de pueblos, lenguas, paisajes, memorias y experiencias). Mediante tales intervenciones enfrenta, por ende, el ethos colonial que atraviesa nuestros cuerpos, interrumpiendo sus prácticas violentas y sus gramáticas opresoras. 


\section{La apertura de la espacialidad educativo-cultural (a modo de cierre)}

Es importante interrogar, por tanto, qué tipo de espacialidad y de temporalidad permite la emergencia de tales experiencias de alteridad, abriendo subjetivaciones contrahegemónicas y disidentes respecto de las matrices de identidad históricamente dominantes que han performado nuestras formas de vida más sedimentadas y su transmisión institucionalizada mediante el fuerte dispositivo central de los sistemas escolares modernos, contemporáneamente persistentes en los marcos de la fundamental inclusión educativa pública.

Volviendo sobre estos aportes, la noción de "espacio educativo-cultural" (Castro, 2018; Enrico, 2018; 2015) que venimos elaborando desde estos cruces transdisciplinarios, nos permite pensar el tránsito de fronteras desde específicas condiciones de conceptualización y territorialidad. Aquí la noción de antagonismo en tanto "límite de lo social" (Laclau y Mouffe, 1987) nos permite a su vez abordar específicos discursos críticos que abren el campo del conocimiento y del saber a una multiplicidad de experiencias transfronterizas - y a una multiplicidad de actores, sujetxs y agenciamientos-, manifiestos en la diversidad de lenguajes y marcos sensibles que alteran la espacialidad educativa tradicional, arrojados al exterior del espacio público amplio y permeados de conflictos entre múltiples sujetos sociales y políticos (lo cual dispersa las fronteras de identidad, al tiempo que hace posibles la transformación social y subjetiva hacia condiciones de comunidad más igualitarias y democráticas, y por tanto menos hostiles y más vivibles).

Desde este tipo de nociones y de prácticas situadas pensamos la incorporación de marcos críticos para habilitar la constante apertura del espacio educativo-cultural, pleno de una riqueza simbólica e imaginaria que busca su transmisión y su recreación permanente.

Volviendo a la lógica educativa y espacial transfronteriza de los talleres, flores menciona:

Estos espacios me permitieron conectarme con docentes, estudiantes, activistas, artistas, académicxs, trabajadorxs, precarixs, de diferentes geografías, nacionalidades, identificación racial / étnica, identidades sexuales y de género, que fueron tensando, problematizando y enriqueciendo mi modo de comprensión de lo educativo y sus intersecciones con procesos de sexualización, generización y racialización. En especial, estos escenarios que yuxtaponían mi experiencia institucional como maestra, mi trabajo como productora y acompañante de escrituras, y los modos de activismo micropolítico que venía desplegando, modelaron una especie de metodología educativa queer o de la disidencia sexual que tramó de manera singular cuerpos, saberes, espacios, afectos, deseos, memorias, erotismos, sensibilidades, escrituras. (Flores, 2018, pp. 142-143)

Es evidente que este tipo de intervención no busca romper de un golpe toda la estructura de la lengua y de las instituciones pedagógicas, con sus códigos hegemónicos de comunicación y transmisión dentro del sistema social (incluida la densa y oscura "otra escena" del inconsciente, del deseo y de los afectos), sino impactarla y transformarla racional y sensiblemente, en marcos de justicia territorial, mediante incisiones que portan en sí mismas un gesto radical, contra toda plenitud universalizante y reproductiva del mundo de la vida (cuya intención de espejo disuelve toda diferencia, y todo deseo o manifestación de alteridad y libertad).

En esta senda es que pensamos necesarias articulaciones abiertas, que nos permitan transitar hacia formas solidarias y no hostiles de comunidad y de igualdad en las diferencias, construyendo una espacialidad democrática e inclusiva donde puedan expresarse nuestros huecos y derivas de saber y de ser, en plena diferencialidad existencial y subjetiva, tanto como nuestros fundamentales acuerdos de igualdad política y social.

\section{Referencias}

Anzaldúa, G. (1999). Borderlands (La frontera): la nueva mestiza. [Trad. C. Valle] (Original publicado en 1987). Capitán Swing.

Aricó, J. (1985). Prólogo. En L. Del Campo (Coord.). Hegemonía y alternativas políticas en América Latina (pp. 11-16). Siglo XXI.

Boria, A. (2016). Operaciones de la teoría feminista. En A. Boria y F. Boccardi (Comps.). Operaciones teóricas 2 (pp. 23-28). El lugar de la teoría. UNC; CEA.

Belausteguigoitia, M. y Mingo, A. (Eds.). (1999). Géneros prófugos. Feminismo y educación. Programa Universitario de Estudios de Género UNAM; Centro de Estudios sobre la Universidad UNAM; Colegio de la Paz Vizcaínas; Paidós Mexicana, Género y Sociedad.

Belausteguigoitia, M. (2012). Teoría crítica y pedagogía. En R. Buenfil, Fuentes, S. y E. Treviño (Coords.). Giros Teóricos II. Diálogos y debates en las Ciencias Sociales y Humanidades (pp. 475-492). Ed. Jornadas, FFyL; UNAM. 
Bidaseca, K. y Vázquez Laba, V. (Comps.). (2011). Feminismos y poscolonialidad. Descolonizando el feminismo desde y en América Latina. Godot.

Britzman, D., Flores, V. y Hooks, B. (2018a). Pedagogías transgresoras 1. [Trad. G. Herczeg] (Original publicado en 2016). Bocavulvaria.

Britzman, D., Lopes Louro, G. y Flores, V. (2018b). Pedagogías transgresoras 2. [Trad. G. Herczeg]. Bocavulvaria.

Butler, J. y Scott, J. (Eds.). Feminists Theorize the Political. Routledge.

Castro, A. (junio de 2018). La espacialidad escolar, lecturas en foco y desplazamientos en la (de)construcción de un objeto. Ponencia presentada en el Taller Espacialidad y arquitectura escolar. DIE Cinvestav, México.

Ciriza, A. (2017). Militancia y academia: una genealogía fronteriza. Estudios feministas, de género y mujeres en Mendoza. Revista Descentrada, 1(1), e004.

Derrida, J. (2010). Seminario La bestia y el soberano, Volumen I (2001 - 2002). Manantial-Bordes.

Enrico, J. (2018a). Lenguas de fuego. Los feminismos del sur y la enunciación teórico-política-corporal-sexual contra las violencias euro-norte-falogocéntricas. Revista Fermentario, 1(12), 74-88. http://www.fermentario.fhuce. edu.uy/index.php/fermentario/article/view/315/400

Enrico, J. (2018b). Escrituras heréticas y transmisión disidente en las pedagogías queer de los feminismos del sur. Valeria Flores y el fuego del desierto. Religación, Revista de Ciencias Sociales y Humanidades, 3(9), 212233. http://revista.religacion.com/article-enrico-juliana-view.html

Enrico, J. (2019). Lenguas desgarradas desde el sur de la vida: políticas-poéticas feministas antagonistas y tránsitos de fronteras queer/cuir en el entrelenguas de val flores. En M. Alvarado (Ed.). Feminismos del sur. Recorridos, itinerarios, junturas. 81-95. Prometeo.

Enrico, J. (2020). Escenas pedagógicas freirianas frente a las matrices de identidad patriarcales y neoliberales: políticas y prácticas de la libertad desde el horizonte emancipatorio de las voces del sur del mundo. En M. Ruiz y M. López (Comps.). Actores pedagógicos y el empoderamiento social: un análisis de las prácticas pedagógicas freirianas. Ed. Universidad Iberoamericana. En prensa.

Flores, V. (2017). Interruqciones. Ensayos de poética activista. Escritura, política, pedagogía (2. ed.). Asentamiento Fernseh.

Flores, V. (2018). Esporas de indisciplina. Pedagogías trastornadas y metodologías queer. En D. Britzman, G. Lopes Louro y v. flores (Coords.). Pedagogías transgresoras 2 (pp. 139-208). Bocavulvaria.
Giroux, H. y McLaren, P. (1998). Sociedad, cultura y educación. Madrid: Miño y Dávila.

Giroux, H. (1998). Las políticas de educación y de cultura. En H. Giroux y P. McLaren (Eds.). Sociedad, cultura y educación (pp. 79-86). Miño y Dávila.

Gramsci, A. (1989). La alternativa pedagógica. Fontamara.

Hall, S. (1996). Introducción ¿Quién necesita "identidad"? En S. Hall y P. du Gay (Comps.). Cuestiones de identidad cultural. 13-39. Amorrortu.

Hooks, B., Brah, A., Sandoval, C. y Anzaldúa, G. (2004). Otras inapropiables. Feminismos desde las fronteras. Traficantes de sueños.

Jameson, F. (1989). Documentos de cultura, documentos de barbarie. La narrativa como acto socialmente simbólico. Visor.

Laclau, E y Mouffe, Ch. (1987). Hegemonía y estrategia socialista. Hacia una radicalización de la democracia. Siglo XXI.

Lacombe, A. (2016). Nota. La potencia de quedarse sin palabras. (Entrevista a María Lugones). Página/12. https://www.pagina12.com.ar/diario/suplementos/ las12/13-10611-2016-05-27.html

Lopes, G. (Comp.). (2001). O corpo educado. Pedagogias da sexualidade. Autêntica.

Lugones, M. (2008). Colonialidady género. Revista Tabula rasa, 9, 73-101. https://doi.org/10.25058/20112742.340

Massey, D. (2005). La filosofía y la política de la espacialidad: algunas consideraciones. En L. Arfuch (Comp.). Pensar este tiempo. Espacios, afectos, pertenencias (pp. 101-128). Paidós.

Mc Laren, P. (1998). Pedagogía crítica, las políticas de resistencia y un lenguaje de esperanza. En H. Giroux y P. McLaren (Eds.). Sociedad, cultura y educación (pp. 215-256). Miño y Dávila.

Mignolo, W. (2003). Historias locales/diseños globales. Colonialidad, conocimientos subalternos y pensamiento fronterizo. Akal.

Mouffe, C. (1999). El retorno de lo político. Paidós.

Preciado, P. (2018). Queer: historia de una palabra. En P. Preciado, P. y Valencia, S. Del Queer al Cuir. ¿Desviaciones o coaliciones? (pp. 9-18). Sudakuir.

Puiggrós, A. (1998). Volver a educar. El desafío de la enseñanza argentina a finales del siglo xx. Ariel. 
Puiggrós, A. (2013). Enfoques de la educación latinoamericana en el siglo XXI. En L. Rodríguez (Dir.). Educación popular en la historia reciente en Argentina y América Latina. Aportes para balance y prospectiva (pp. 9-18). APPEAL.

Quijano, A. (2000). Colonialidad del poder, eurocentrismo y América Latina. En Lander, E. (Ed.). Colonialidad del saber, Eurocentrismo y Ciencias Sociales (pp. 776-832). CLACSO; UNESCO.

Richard, N. (2012). Humanidades y ciencias sociales. Travesías disciplinarias y conflictos en los bordes. En Buenfil, R., Fuentes, S. y Treviño, E. (Coords.) Giros teóricos II. Diálogos y debates en las ciencias sociales y humanidades (pp. 23-42). FFL; UNAM.

Ruiz Muñoz, M. y Franco García, M. (2017). Narrativas biográficas a contracorriente. En M. Ruiz Muñoz y M. Franco García (Coords.). Voces de la alteridad. 13-52. Universidad Iberoamericana - Cuidad de México.

Sandoval, C. (2004). Nuevas ciencias. Feminismo cyborg y metodología de los oprimidos. En b. hooks, A. Brah, Sandoval, C. y G. Anzaldúa, G. (Coords.). Otras inapropiables. Feminismos desde las fronteras (pp. 81-106). Traficantes de sueños.
Segato, R. (2010). Las estructuras elementales de la violencia. Ensayos sobre género entre la antropología, el psicoanálisis y los derechos humanos. Prometeo.

Segato, R. (2016). Contra-pedagogías de la crueldad (Conferencias). [Video]. YouTube. https://www.youtube.com/ watch?v=17ijWDlok2g

Spivak, G. (1998). ¿Puede hablar el sujeto subalterno? Obius Tertius, 3(6), 175-235.

Tadeu da Silva, T. (1999). Documentos de identidad. Una introducción a las teorías del currículo. Auténtica Editorial.

Tadeu da Silva, T. (2001). Espacios de identidad. Nuevas visiones sobre el curriculum. Octaedro.

Valencia, S. (2014). Capitalismo gore. Publicación del Programa Universitario de Estudios de Género; UNAM.

Valencia, S. (2018). Del Queer al Cuir. Ostranénie geopolítica y epistémica desde el sur g-local. En P. Preciado y S. Valencia, Del Queer al Cuir. ¿Desviaciones o coaliciones? Sudakuir.

Williams, R. (1997). Marxismo y literatura. Península. 